This series on glass successfully summarizes research over the past decade and serves as an introduction to the glass science and technology over this period. These volumes can be recommended to all levels of glass scientists from graduate students to industrial laboratory scientists.

Reviewer: Itaru Yasui is an associate professor at the Center for Adunaned Materials, Institute of Industrial Science, University of Tokyo. He reccived his Dr. Eng. degree from the University of Tokyo in 1973.

\section{Advanced Ceramic Materials: Technological and Economic Assessment}

(Noyes Publications, 1985)

This book is based on findings of previous reports prepared by the Charles River Associates (Terhnological Assessment of Adranced Ceramic Materials, August 1984), the Office of Industry Assessment ( $A$ Competitive Assessment of the U.S. Aduniced Ceramics Industry, March 1984), and the Committee on the Status of High Technology Ceramics in Japan (High Terhnology Ciramics in Japan, 1984).

The first cited report uses, as case studies, the topics of heat engine applications, capacitors, integrated optic devices, toxic and combustible gas sensors, and cutting tools. For each of these case studies, the book completely covers the technological status of its application, including current technological barriers or future areas of research with anticipated technological and economic benefits. The section on high technology ceramics in Japan gives an insight in to the management of research and development programs through a system which includes the participation of business, government, universities, and national laboratories. This section also lists mutually beneficial areas of cooperation between Japan and the United States.

The technical considerations in this book are discussed at an elementary level and, presumably, were not intended for specialists in the given area. However, the general approach adopted by this book provides a broad and valuable overview of the current status of and future trends in advanced ceramic materials. The information is of interest to scientists, engineers, policymakers, and entrepreneurs.

Reviewer: Z.A. Munir is a professor in the Division of Materinls Science and Enginering and associate de'an for graduat' studies, Collige of Enginering, Lniversity of Californin-Davis.

MIRS

\section{EDITOR'S CHOICE}

Figures appearing in th' EDITOR'S CHOICE are those arising from materials resenth which strike the editor's fancy as being aesthetically appealing and eye-catching. No further criteria are applied and non' should be assumed. Submissions of candidate figure's are welcome and should ind lute a complete' source citation, a photocopy of the report in which it appears (or will appear), and a reproductionquality original drawing or photograph of the figure in question.

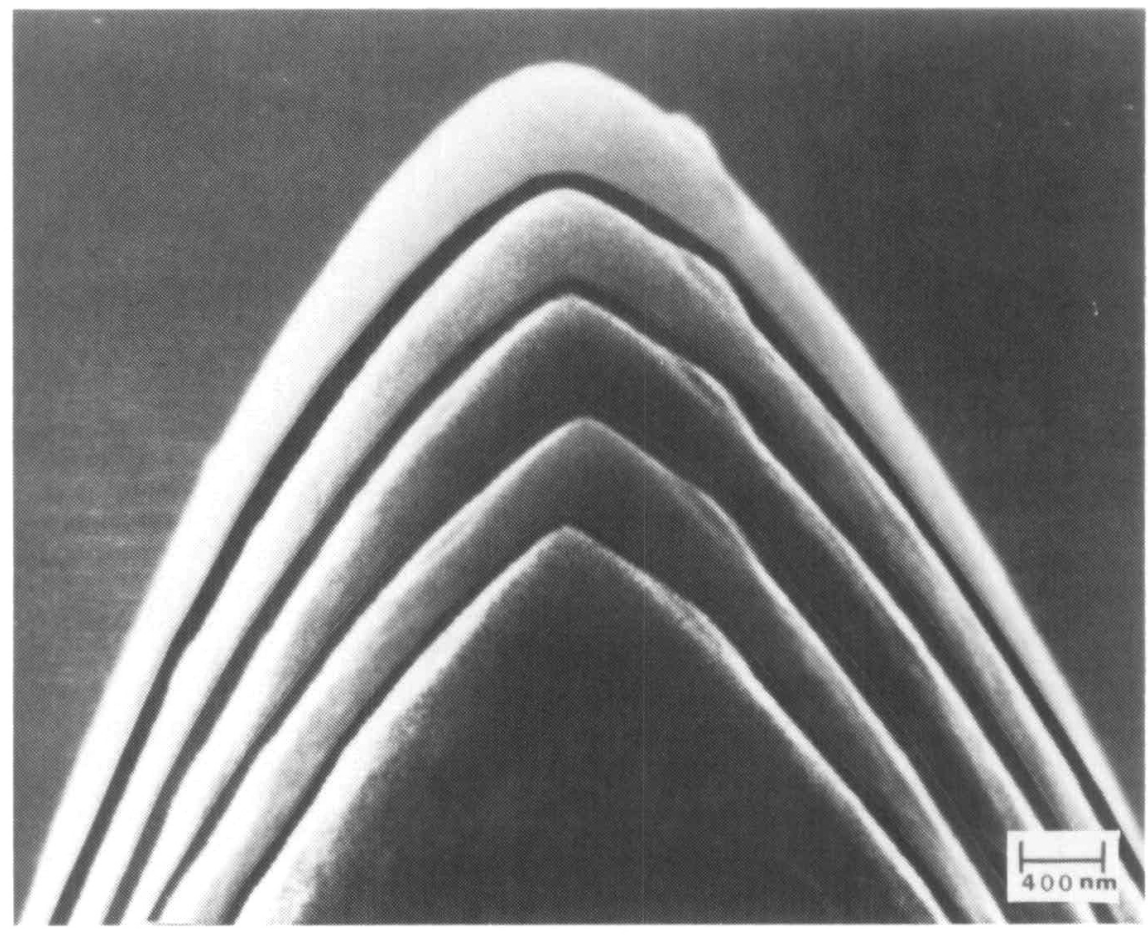

The EDITOR'S CHOICE for this issue of the BULLETIN comes from the work of J. A. Kubby and B. M. Siegel who studied the evolution of sputter-eroded surfaces for application to the formation of field-ion emitting tips. This figure is from their paper in Jourmal of Vacumm Science and Téhnology (B4(1) Jan/Feb 1986, p. 120-125). It shows the successive stages of erosion of a tungsten single crystal wire subjected to ion milling at room temperature by $4 \mathrm{keV}$ argon ionscollimated along the axis of the wire which is also its $<100\rangle$ crystallographic axis. The original parabolic profile at the top first loses its radius of curvature at the apex and then the apex angle continues to decrease. The incremental argon fluence between SEM examinations was $5.6 \times 10^{18}$ Ar $/ \mathrm{cm}^{2}$ delivered in 15 minutes. For the sake of exposition and comparison with a model for the erosion process, the authors chose to overlay five separate SEM micrographs, giving the impression of nested arches reminiscent of those seen in the architecture of cathedrals or in the harbor view of the Sydney Opera House.

\section{ERRATA}

In "Damage Mechanisms in Optical Materials for High-Power, ShortWavelength Laser Systems" (May/June issue, page 46) "104 photons per surface site" should read " $10^{4}$ photons per surface site. 